\title{
Por uma avaliação objetiva e fundamentada: a escolha do livro didático de História
}

\section{Bruno Rafael Machado Nascimento ${ }^{1}$}

1 Mestrando em Ensino de História (UNIFAP), Especialista em Metodologia do ensino de História e Geografia (UNINTER), Especialista em Ensino Religioso (FATECH) e Licenciado e Bacharel em História (UNIFAP). Professor efetivo de História do Governo do Estado do Amapá, Brasil. E-mail: brunomachado8@outlook.com

RESUMO: Este artigo caracteriza-se como de revisão bibliográfica, no qual foram utilizados, principalmente, livros e dissertações de autores que pesquisam sobre o livro didático e a didática da história. O objetivo é descrever quais os critérios que os educadores da disciplina de história, nos anos finais do ensino fundamental, podem utilizar para subsidiar suas escolhas do livro didático mais apropriado, pois no cotidiano escolar cabe aos professores essa tarefa. Com este material foram feitas análises comparativas dos critérios propostos pelos autores para escolha do melhor livro de história. Utilizou-se, principalmente, como referencial teórico Bittencourt (2008; 2009) e Rüsen (2011), autores que foram essenciais para alcançar os objetivos. Verificaram-se, entre os autores, critérios comuns que devem nortear a prática de escolha.

Palavras- chave: Ensino. Professores. Educação.

For an objective and reasoned assessment: the choice of history textbook ABSTRACT: This article is characterized as a bibliographic review in which were used mainly books and dissertations authors researching on the textbook and the teaching of history. The aim is to describe the criteria that educators of the discipline of history, in the final years of elementary school, can use to support their choice of the most appropriate textbook, because it is in the daily school teachers this task. With this material were made comparative analysis of the criteria proposed by the authors to choose the best history book. It was used mainly as a theoretical Bittencourt $(2008 ; 2009)$ and Rüsen (2011) authors that were essential to achieve the objectives. They are found among the common criteria that authors should guide the practice of choice.

Keywords: Education. Teachers. Education.

\section{INTRODUÇÃO}

A cada dia, na teia da vida profissional, os mestres são constantemente pressionados pela escola, sociedade, pais, alunos e por si mesmos enfrentando diversas dificuldades para executar suas atividades a favor da aprendizagem dos alunos. Diante dessa realidade, uma tarefa que aparentemente é menor pode passar despercebida, ou seja, a escolha do livro didático. Faz parte da vida docente da escola pública escolher o livro que se pretende trabalhar por um período mínimo de três anos. E esse é o foco desta pesquisa, isto é, analisar os critérios que podem subsidiar a escolha do livro didático de história nos anos finais do ensino fundamental. 
Sendo assim, a problemática que moveu este estudo foi: quais critérios podem ser utilizados por professores de história dos anos finais do ensino fundamental na escoIha do livro didático? Para responder ao problema proposto utilizaram-se livros e dissertações que tratam da referida questão com o intuito de analisar quais seriam os critérios propostos pelos pesquisadores. Como principais referências teóricas, têmse a professora Circe Maria Bittencourt (2008; 2009), reconhecida nacionalmente por suas pesquisas sobre o ensino de história e, mormente, o livro didático; e o alemão Jörn Rüsen (2011), com a reflexão sobre a teoria do ensino de história, destacando seus conceitos de consciência histórica e aprendizagem histórica.

Não resta dúvida que o livro didático é instrumento fundamental no exercício da docência, pois em muitas realidades é o único material disponível. Além disso, esse objeto didático "é um dos principais instrumentos de mediação, seleção e organização dos saberes escolares a serem ensinados" (ESPÍNDOLA, 2003, p. 26). Este fato é inegável na prática pedagógica dos professores e os de história não fogem à regra, pois devido à falta de tempo, estrutura das escolas, baixa remuneração e desvalorização, não utilizam outros instrumentos. Dessa forma, o livro didático de história, além de ser o principal e talvez o único recurso didático utilizado pelo professor, é bastante complexo e possui diversas funções. Para ser bem aproveitado, este material precisa ser fruto de uma avaliação assentada em critérios fundamentados e objetivos.

Este artigo está organizado da seguinte maneira: inicialmente com uma análise conceitual acerca do livro didático em suas múltiplas funções; depois se passa à temá- tica central, ou seja, a análise dos principais critérios a serem utilizados na escolha do livro didático de história; por fim as considerações finais, nas quais são retomadas as ideias trabalhadas ao longo do texto.

\section{LIVRO DIDÁTICO E AS SUAS FUNÇÕES}

\subsection{0 que é o livro didático?}

É importante especificar como se compreende o livro didático, ou seja, qual o conceito adotado. Tem-se, portanto, o livro como um:

Objeto cultural de difícil definição, por ser obra bastante complexa, que se caracteriza pela interferência de vários sujeitos em sua produção, circulação e consumo. Possui ou pode assumir funções diferentes, dependendo das condições do lugar e do momento em que é produzido e utilizado nas diferentes situações escolares. É um objeto de 'múltiplas facetas', e para sua elaboração e uso existem muitas interferências (BITTENCOURT, 2009, p.301).

Para Circe Maria Bittencourt (2009) que há anos pesquisa sobre o livro didático, este objeto bastante utilizado nas salas de aula não é meramente um livro que traz informações. Ele é bastante complexo, pois traz um conjunto de ideias, vários profissionais participam da sua elaboração e não somente o autor, dependendo da forma de uso ele adquiri funções diferentes. Não resta dúvida que ele faz uma espécie de mediação didática entre o saber acadêmico e o escolar, como asseveram Berutti e Marques (2009, p. 97):

Um instrumento pedagógico ou de um depositário de conteúdos, ele ocupa lugar

https://periodicos.unifap.br/index.php/estacao Macapá, v. 6, n. 2, p. 79-89, maio/ago. 2016 
de destaque na intermediação entre saber científico, multifacetado, produzido nas universidades, e o saber didático, recortado, fruto de uma transposição, que é apresentado e desenvolvido em sala de aula.

É possível perceber nestes conceitos o quanto o livro didático precisa ser percebido pelo professor nas suas múltiplas peculiaridades. Observa-se por meio da bibliografia analisada, que os pesquisadores são unânimes em afirmar que "as pesquisas atuais continuam apontando o livro didático como o principal, quando não o único, material utilizado nas aulas de História" (ESPÍNDOLA, 2003, p. 46). Segundo Mantovani (2009) o livro didático é um instrumento importante na relação ensino-aprendizagem que, para muitos professores, é o único material de trabalho e para outros é um material de apoio para as suas aulas, porém, nenhum abre mão do livro didático.

Por isso, concorda-se com Bittencourt $(2009$, p. 300$)$ quando afirma que "muito criticados, muitas vezes considerados os culpados pelas mazelas do ensino de história, os livros didáticos são invariavelmente um tema polêmico".

Toma-se posição neste artigo de que o livro didático é um material importantíssimo para o fazer pedagógico do professor de história, visto que, é um sistematizador "dos conteúdos que devem ser trabalhados em classe e de ser instrumento de apoio para o professor e suporte teórico e prático para o aluno" (MANTOVANI, 2009, p.23). Portanto, o professor precisa compreender as funções deste instrumento para uma boa escolha e, por conseguinte, um bom trabaIho com seus alunos.

\subsection{As funções do livro didático}

É inegável que a qualidade do livro didático tem melhorado consideravelmente ao longo dos últimos anos. Fruto de pesquisas em torno dos diversos aspectos do livro, bem como, da avaliação, compra e distribuição para as escolas públicas realizadas pelo MEC por meio do Programa Nacional do Livro Didático (PNLD). Como pode-se perceber:

É indiscutível o fato de que a ampla distribuição de livros didáticos trouxe novas perspectivas para o ensino, possibilitando a melhoria dos processos de ensinoaprendizagem. De qualquer modo, tanto na utilização dos livros quanto na sua seleção, é imperioso que os educadores saibam reconhecer e avaliar características relevantes, que possam atestar a qualidade desses livros ou refutá-la (CARVALHO, 2009, p. 63).

Concorda-se com Carvalho (2009), quando discorre sobre a importância dos professores elaborarem critérios para a escolha de um livro que atenda suas necessidades e de seus alunos. Para tanto é indispensável o conhecimento das funções deste material didático.

Corrobora-se com o pensamento de $\mathrm{Ri}$ chaudeau $(1979$, p.25) sobre as funções dos livros quando assevera que:

A primeira é a função de informação e todas as implicações que dela advêm. A segunda função é a estruturação e organização da aprendizagem dos estudantes. A última função, considerando que o livro didático não pode ser por si mesmo um fim, é a de guiar os alunos em sua apreensão do mundo exterior, em colabora- 
ção com outros conhecimentos adquiridos em outros contextos distintos do escolar.

Como dito anteriormente, o didático possui inúmeras funções no contexto escolar, por exemplo, é um instrumento de organização dos objetivos de aprendizagens dos alunos. Por sua importância, ele tornouse objeto de pesquisa de vários estudiosos da área educacional. Esses estudos foram importantes, pois revelaram algumas limitações do livro, como afirma Bittencourt (2009, p. 300) "as críticas em relação aos livros didáticos apontam para muitas de suas deficiências de conteúdo, suas lacunas e erros conceituais ou informativos".

A pesquisadora Circe Bittencourt (2008), ao analisar os manuais didáticos, chama atenção para o aspecto que ele é também uma mercadoria ligada à indústria cultural, pois "em sua construção interferem vários personagens, iniciando pela figura do editor, passando pelo autor e pelos técnicos especializados dos processos gráficos, como programadores visuais, ilustradores" (BITTENCOURT, 2008, p.70).

Percebe-se que na citação a autora considera o livro como uma mercadoria que precisa ser comercializada para atender os interesses do capital e, para atingir seus objetivos, as editoras possuem uma gama de profissionais que adaptam o escrito do autor ou autores do livro para atender as demandas do mercado.

Para Bittencourt (2008, p.72), o livro didático também tem a função de depositário dos conteúdos escolares, pois é: "suporte básico e sistematizador privilegiado dos conteúdos elencados pelas propostas curriculares; e é por seu intermédio que são passados os conhecimentos e técnicas con- sideradas fundamentais de uma sociedade em determinada época".

Bittencourt (2008) aponta que o livro incorpora certas propostas curriculares que estão em voga na sociedade e são exigidas pelos órgãos responsáveis por elaborar e cobrar determinadas temáticas como, por exemplo, a obrigatoriedade do ensino da História e cultura africana e afro-brasileira, bem como, a história e cultura indígena e ainda outras temáticas não oficialmente obrigatórias, mas que devido à pressão dos movimentos sociais tornaram-se valorizadas, nas quais, citam-se as relações de gênero ao longo da história da humanidade.

Também Bittencourt (2008) considera o livro com a função de veículo de sistema de valores e instrumento pedagógico. Isso significa que ele transmite uma determinada visão de mundo que pode explicitar a realidade ou, ao contrário, mascará-la. O livro traz consigo certa concepção pedagógica que pode ajudar o aluno no desenvolvimento de uma atitude crítica e autônoma ou num mero reprodutor de discursos. Logo, o professor tem que estar consciente destas funções, pois o livro não é imparcial. Como citado anteriormente, ele tem diversas facetas que o professor precisa levar em consideração na hora da sua análise. O referido material pedagógico exigirá do "mestre" certas habilidades.

Diante da análise obtida sobre as funções de um livro didático (entre eles o de história), pode-se perceber que o trabalho do professor de história requer escolhas fundamentadas, tempo suficiente e critérios acertados. Logo, a escolha do melhor livro deve levar em consideração as condições reais em que o profissional está inserido. Portanto, concorda-se com Bittencourt $(2008$, p. 73$)$ quando assevera que: "os usos 
que professores e alunos fazem do livro didático são variados e podem transformar esse veículo ideológico e fonte de lucro das editoras em instrumento de trabalho mais eficiente e adequado às necessidades de um ensino autônomo".

\section{OS CRITÉRIOS A SEREM UTILIZADOS PE- LOS PROFESSORES DE HISTÓRIA NA ESCO- LHA DO LIVRO DIDÁTICO}

Antes de tudo, afirma-se que esses critérios não são "camisas de força" que devem ser seguidos religiosamente, mas devem ser adaptados à realidade escolar e à concepção metodológica do professor, isto é, trata-se de um esforço de orientação para a melhoria na qualidade do ensino de história, pois, esse instrumento didático é fundamental na prática pedagógica do professor.

Sabe-se que os educadores elaboram, cada um ao seu modo como fruto da sua prática em sala de aula, alguns critérios. 0 que se pretende são orientações gerais, pois:

Ao se considerar as dimensões das formas de consumo do livro didático, não se pode omitir o poder do professor. Cabe a este, na maioria das vezes, a escolha do livro, e sua leitura em sala de aula é determinada também pelo professor. Os capítulos selecionados, assim como as tarefas decorrentes da leitura, são opções exclusivas do professor, mesmo quando inseridas e limitadas por projeto pedagógico estipulado pela escola (BITTENCOURT, 2008, p.74).

Bittencourt (2008), nesta citação, revela o papel fundamental do professor em relação ao uso do livro didático, assim como,
Carie (2008) mostra que os estudos sobre os livros didáticos têm demonstrado que leitores com visões de mundo diferentes, orientados por práticas de leituras distintas, podem apropriar-se de um mesmo texto de formas distintas. Além disso, o "professor se apropria desses livros de acordo com sua formação, a sua experiência profissional, as suas concepções de ensino, etc" (CARIE, 2008, p.40).

Além da apropriação que professores e alunos fazem do livro didático de história, outros fatores influenciam na qualidade de ensino:

Desse modo, ainda que as escolas adotem bons livros, isso não implicará em melhoria direta na qualidade do ensino, ou seja, o uso de um livro didático está relacionado à formação do professor, ao tamanho das turmas, à infra-estrutura da escola, à presença de outros materiais didáticos, etc" (CARIE, 2008, p.40).

O livro por si só, mesmo com a qualidade comprovada, não garante uma aprendizagem adequada. Diversos fatores influenciam no sucesso do ensino e aprendizagem. Aqui o papel do professor é central, pois é ele que construirá metodologias para o uso adequado deste material didático. Sabe-se que na prática escolar, em geral, cabe ao professor a escolha do livro didático. Para Carvalho (2009, p.94-95).

Cabe ao professor a responsabilidade da análise e do estudo dos livros didáticos a serem adotados. Fazendo uma seleção criteriosa dos livros didáticos, o professor deverá escolher quais usos fará de forma a desenvolver a criatividade nos alunos, a capacidade crítica e a ação argumentativa e comunicativa dos assuntos abordados . 
Assim como as autoras citadas, é dada a importância do professor de história na forma que utiliza o livro. Sabe-se que nem ele e nem o aluno são passíveis diante do livro, no entanto, também é inegável o papel do manual de história na relação ensino-aprendizagem nas escolas do país. Segundo Santos (2007), o professor exerce um importante papel ao escolher um determinado livro didático, pois é devido a sua prática pedagógica, que se concretiza as políticas públicas voltadas para o este material pedagógico.

Nenhuma das bibliografias analisadas desmereceu o papel do livro didático nas aulas, isso mostra o quanto este material é importante. Se for dessa forma, o mesmo merece ser analisado criteriosamente com fundamentos e objetivos.

Parte-se da premissa de que o professor de história sabe escolher muito bem o livro e utilizá-lo em sala. O bom professor saberá aproveitar um livro didático limitado, mas um livro de melhor qualidade para a sua realidade certamente contribuirá para a qualidade do ensino de história.

Quais critérios adotar para a escolha do livro didático? Baseada numa pesquisa de dissertação de mestrado sobre as leituras do livro didático de história nos anos finais do ensino fundamental, Carvalho (2009) assevera que os critérios para avaliar o livro didático de história são: Iconografia, Adequação ao conteúdo trabalhado, usabilidade, estética e aspectos pedagógicos.

Refletindo sobre a iconografia, que deve ser analisada pelo educador, a autora afirma:

A avaliação da iconografia do livro didático tem um papel de grande importância na identificação de sua qualidade como instrumento de aprendizagem. Uma iconografia variada e bem selecionada pode ter uma influência positiva tanto na usabilidade do livro (facilidade do uso) quanto em sua eficiência nos processos de aprendizagem (CARVALHO, 2009, p.69).

A iconografia presente no livro didático deve ser bem analisada pelo professor, pois muitas imagens criam estereótipos de certos grupos sociais, como por exemplo, dos povos indígenas como mostrou Bittencourt (2008) em sua análise sobre as representações feitas sobre esses povos. Segundo Bittencourt (2008), ao realizar a análise da iconografia presente no livro de história, é preciso que o professor faça uma leitura crítica, ou seja, perceba qual a ideia transmitida pela imagem, se ela traz as referências como o nome do autor, o ano, qual foi o objetivo do autor, para quem se destinava a obra, e ainda, se as imagens estão bem dispostas no livro, se estão de acordo com o texto escrito e se possuem boa qualidade gráfica. Neste aspecto é importante o professor avaliar se elas não são apenas ilustrações.

O segundo critério apresentado por Carvalho (2009) é a adequação ao conteúdo trabalhado, ou seja, se a linguagem trabaIhada pelo livro é acessível aos alunos e se está de acordo com a capacidade cognitiva deles. Este critério leva a alertar os professores de que não adianta o livro ser bom para o professor e o aluno ser incapaz de compreender devido à linguagem ser inacessível para as suas condições cognitivas. Constantemente, testemunha-se que o aluno reclama por não entender as palavras difíceis, logo, o professor deve estar atento a este critério e, claro, levar em considera- 
ção a realidade dos seus alunos.

O terceiro critério é a usabilidade, ou seja, "de uma maneira geral, busca-se verificar se os mecanismos de interação do material didático são facilmente identificáveis e se a sua utilização é intuitiva" (CARVALHO, 2009, p.71). Aqui deve-se atentar para a capacidade de o livro ser realmente utilizado pelo educador e pelos alunos, ou seja, se ele pode ser facilmente manuseado, se os capítulos estão bem-dispostos e estruturados.

O quarto critério é a estética, ou seja, "é importante identificar se o livro didático emprega recursos gráficos que melhoram seu aspecto estético, tornando mais aprazível sua utilização" (CARVALHO, 2009, p.71). São comuns os casos em que alguns professores de história afirmam que quanto mais colorido, melhor será o livro, pois, dessa forma, chamaria a atenção dos alunos pouco interessados na leitura. No entanto, esta questão precisa ser observada com cautela, pois as cores precisam está bem organizadas para não correr o risco de uma poluição visual e atrapalhar o ensino-aprendizagem.

O quinto e último critério elencado por Carvalho (2009) é o aspecto pedagógico, ou seja, é necessário que o professor identifique qual a concepção pedagógica do livro. Muitos professores de história não analisam esse aspecto que, no entender geral, é essencial. Deve-se verificar que tipos de atividades são propostas, se levam em consideração a experiência histórica do próprio aluno, se o reconhece e o leva a reconhecerse como sujeito histórico; se o livro trabalha somente com a memorização ou traz questões atuais para uma análise crítica da sociedade. Enfim, neste critério é preciso que as propostas das atividades conduzam os alunos à autonomia do pensamento e não apenas à reprodução de discursos sem sentido para as suas vidas.

Para Bittencourt (2009), é importante para análise do livro didático de história, três aspectos básicos: a forma, o conteúdo histórico escolar e seu conteúdo pedagógico. Será analisado cada aspecto levantado pela autora e as semelhanças que possui sua proposta com a da pesquisadora CarvaIho, vista anteriormente.

Segundo Bittencourt (2009) o professor precisa levar em consideração a forma do livro, ou seja:

A análise da forma inclui uma visão da apresentação gráfica do conjunto da obra e de como estão divididos seus diferentes tópicos característicos, os quais podem facilitar o trabalho dos alunos: introdução ou apresentação da obra, índice, glossários, bibliografia (BITTENCOURT, 2009, p.312).

Nesta citação pode-se relacionar este critério proposto pela a autora com o critério de usabilidade proposto por Carvalho (2009), ou seja, a estruturação gráfica da obra deve facilitar o uso pelos alunos. Logo, um livro bem estruturado como proposto pelas autoras será muito mais aproveitado nas situações didáticas.

É importante os educadores estarem atentos neste aspecto da forma com os mecanismos criados pelas editoras, pois, como ressalta Bittencourt (2009, p. 311-312): "oferecem-Ihes cursos, criam materiais anexos que acompanham as obras e esmeramse em apresentar o livro como um produto 'novo', seguidor das últimas inovações pedagógicas ou das propostas curriculares mais atuais".

E ainda, Cassiano (2007) segue o mesmo 
raciocínio da autora ao chamar atenção para as investidas das editoras para seduzir o professor na hora da escolha, como por exemplo: guias não oficiais, distribuição de materiais, palestras, realização de oficinas, brindes. Portanto, o professor não deve nunca perder de vista que o livro é uma mercadoria que precisa ser vendida, fazer uma avaliação criteriosa neste aspecto e não deixar-se seduzir pelas investidas das editoras.

Com relação ao critério dos conteúdos históricos escolares, Bittencourt (2009) percebe que o livro é um depositário de um determinado conhecimento histórico, logo o professor deve identificar a concepção de história do autor. Ela salienta que há certo ecletismo que dificulta o trabalho de identificação. No entanto, a análise da bibliografia, seleção de documentos ou excertos de determinadas obras historiográficas contribuirá para a percepção da tendência historiográfica predominante.

Chama-se atenção para que os professores percebam se as obras possuem documentos históricos para serem trabalhadas com os alunos de forma contextualizada. Concorda-se com Bittencourt (2009) que se deve verificar se existem leituras complementares para professores e alunos, pois é importante para verificação. Além desse aspecto, para Bittencourt (2009, p. 315) "é importante perceber a concepção de conhecimento expressa no livro; ou seja; além de sua capacidade de transmitir determinado acontecimento histórico, é preciso identificar como esse conhecimento deve ser aprendido".

Neste ponto há uma relação entre o que propõe Bittencourt (2009) e Carvalho (2009), isto é, ambas afirmam que é preciso atentar para as atividades propostas pelo livro, identificando se vão além das memorizações e se levam os alunos à construção de comparações, realização de semelhanças e diferenças entre os acontecimentos históricos.

Rüsen (2011) utiliza entre outros conceitos: educação histórica, aprendizagem histórica e principalmente $\mathrm{o}$ de consciência histórica, que em resumo é a,

Atividade mental da memória histórica, que tem sua representação em uma interpretação da experiência do passado encaminhada de maneira a compreender as atuais condições de vida e a desenvolver perspectivas de futuro na vida prática conforme a experiência (RÜSEN, 2011, p. 112).

Para o autor, esta consciência não é meramente uma descrição do passado, mas um caminho para compreender o presente e visualizar o futuro. Concorda-se com $\underline{\text { Rü- }}$ sen (2011) que a consciência histórica ajuda na constituição da identidade e serve para a orientação da vida prática. Segundo Rüsen (2011, p.112), a verdadeira finalidade de um livro de história é: "tornar possível, impulsionar e favorecer a aprendizagem da história". E a "aprendizagem da história é um processo de desenvolvimento da consciência histórica no qual se deve adquirir competências da memória histórica" (RÜSEN, 2011, p.113). De posse do entendimento do conceito de consciência histórica, serão analisadas as propostas para um bom livro elencadas por Rüsen (2011).

Para Rüsen (2011), o livro deve ter um formato claro e estruturado, ou seja:

Serão convenientes um modelo claro e simples, uma distribuição e uma estruturação claras de todos os materiais, ajuda Macapá, v. 6, n. 2, p. 79-89, maio/ago. 2016 
para a orientação na forma de títulos e indicações e, também, um anexo que inclua um índice, um glossário com explicações dos termos e nomes mais importantes e uma bibliografia com livros apropriados para ampliar os temas (RÜSEN, 2011, p.115).

No trecho, percebe-se uma relação entre os três autores que servem de referencial teórico para responder a problemática, isto é, tanto Carvalho (2009), Bittencourt (2009) quanto Rüsen (2011) chamam a atenção para o aspecto gráfico do livro que precisa está devidamente estruturado para facilitar a aprendizagem histórica.

Segundo Rüsen (2011), o livro deve possuir uma estruturação de materiais de tal forma que os próprios alunos sejam capazes de identificar suas intenções didáticas, os pontos fundamentais dos conteúdos e os conceitos metodológicos do ensino.

Outro aspecto levantado por Rüsen (2011) é a relação do livro com o aluno, ou seja, este instrumento pedagógico tem que levar em consideração a capacidade cognitiva dos alunos, que se manifesta no nível de linguagem utilizada. Também se associa ao critério de adequação ao conteúdo trabalhado proposto por Carvalho (2009), no qual, também reflete sobre a problemática da linguagem nos livros de história. Porém, percebe-se que diversos livros possuem simplificações de conceitos históricos na tentativa de facilitar a compreensão dos alunos, ou seja, não se pode aceitar um livro superficial do ponto de vista historiográfico com a justificativa de possuir uma linguagem acessível.

Para o autor alemão:

Todavia, a matéria apresentada tem que

Estação Científica (UNIFAP)

ISSN 2179-1902 guardar uma relação com as experiências e expectativas dos alunos e alunas, sobretudo com seu apego geral, específico de cada geração, de suas próprias oportunidades na vida, bem como com as experiências cotidianas, como é a situação da infância e juventude, do colégio e também do conflito de gerações. Contudo, as experiências históricas, interpretações e orientações do horizonte de experiências e expectativas do aluno naturalmente têm que ser relativizadas. (RÜSEN, 2011, p. 116).

Concorda-se com este autor ao relacionar a história com a vida do aluno, principalmente no sentido do conhecimento histórico responder às indagações do presente. Portanto, o conhecimento histórico tem que ser apreendido pelos alunos e ajudá-los em suas vidas cotidianas.

Por fim, trata-se da relação do livro com a sala de aula, como afirma Rüsen (2011, p.117), "um livro didático somente é útil se realmente se pode trabalhar com ele em sala de aula." Aqui ele reflete sobre a necessidade do livro conter várias perspectivas ou versões históricas. Por meio de materiais adequados,

Tem que se demonstrar aos alunos e alunas que o mesmo fato pode ser percebido pelos afetados de forma diferente e inclusive contrária. Portanto,para apresentar a experiência histórica partindo de várias perspectivas, os conflitos serão particularmente adequados. Graças a este tipo de exposição, a experiência histórica perde a falsa aparência de objetividade; o passado ganha vitalidade e estimula, inclusive antes da percepção empírica, uma atividade interpretativa da consciência histórica dos alunos e alunas (RÜSEN, 2011, p.122). 
Compreende-se, por meio dessa citação, que o livro didático de história deve possuir diversas versões sobre os eventos históricos e não apresentar uma visão dogmática e assim, revelar o conhecimento histórico como um processo sempre em construção. Logo, devem trazer documentos históricos que incentivem os alunos a exercitar a capacidade de argumentação, crítica e julgamento numa perspectiva histórica. A proposta de análise do historiador alemão é semelhante ao que refletiu-se sobre os aspectos pedagógicos com Carvalho (2009) e Bittencourt (2009), pois ambas enfatizam a possibilidade do incentivo à autonomia dos alunos, citados anteriormente.

\section{CONSIDERAÇÕES FINAIS}

Ao longo desse artigo teve-se a oportunidade de compreender as várias facetas e funções do livro didático, ou seja, é um material multifacetado. Daí a necessidade de revelar os diversos aspectos desse objeto para auxílio em estabelecer critérios fundamentados na escolha do livro didático de história. Observou-se os pontos negativos que os manuais podem conter, bem como, os positivos. Este instrumento é usado para economizar tempo no preparo das aulas, localizar leituras extras, exercícios, oficinas (CARVALHO, 2009). Constatou-se que na realidade brasileira o livro didático "assume a forma de currículo, 'organiza', define o planejamento escolar" (CARVALHO, 2009, p.89).

Refletiu-se sobre alguns critérios de escolha do livro propostos por especialistas na área do ensino de história, pois, como foi detectado, este material é irrenunciável na prática pedagógica do professor. Certamente, foi levado em consideração que tanto professores quanto alunos apropriam-se do livro, reinventado-o. E isso deve realmente ser feito, mas a escolha a partir de critérios objetivos, aliados com a realidade e a experiência do professor, renderá bons frutos em sala de aula. Reafirma-se que os critérios aqui analisados são pistas que os professores podem orientar-se e não "camisas de força" que prendam os profissionais.

Destarte, percebeu-se que os autores referenciados concordam em diversos critérios, a saber: a linguagem do livro didático de história que deve está de acordo com a capacidade cognitiva dos educandos, ou seja, uma linguagem excessivamente técnica inviabiliza a aprendizagem. O cuidado com a iconografia disposta nos livros é fundamental, pois como discutiu-se ela apenas reforça o que o texto escrito afirma e, mais grave, reforça preconceitos contra determinados grupos sociais e étnicos. Outro aspecto fundamental diz respeito aos conteúdos históricos que, muitas vezes, apresentam diversas interpretações e um bom livro deve trazer essas várias versões para que os alunos tomem consciência que o conhecimento histórico é construído a partir de problemáticas distintas. A organização gráfica do sumário, capítulo e temas é importante como facilitadora para os estudantes identificarem o que procuram. O aspecto pedagógico do livro deve ser analisado, por exemplo, como são elaboradas as perguntas? Elas visam o caráter interpretativo ou a mera memorização? O livro deve ajudá-los a desenvolver o pensamento autônomo e crítico.

Enfatizou-se o livro didático de história, mas sozinho não será capaz de promover o ensino de história de qualidade. O professor além de fazer uma boa escolha, deverá sabê-lo usar para alcançar os objetivos. Nada 
substitui o papel do professor.

\section{REFERÊNCIAS}

BERUTTI, F.; MARQUES, A. Ensinar e aprender História. Belo Horizonte: RHJ, 2009.

BITTENCOURT, C. M. F. Ensino de História: fundamentos e métodos. 3. ed. São Paulo: Cortez, 2009.

. Entre textos e imagens. In:

saber histórico na sala de aula. 11. ed. São Paulo: Contexto, 2008. p. 69-90.

CARIE, N. S. de. Avaliações de coleções didáticas de História de 5a a 8 a série do ensino fundamental: um contraste entre os critérios avaliativos dos professores e do Programa Nacional do Livro Didático. 2008. 139 f. Dissertação (Mestrado em Educação) - Universidade Federal de Minas Gerais. Belo Horizonte, 2008.

CARVALHO, A. B. dos S. Leituras e usos do livro didático de História: relações professor-livro didático nos anos finais do ensino fundamental. 2009. 120 f. Dissertação (Mestrado em Educação) - Universidade Federal de Uberlândia. Uberlândia - MG, 2009.

CASSIANO, C. C. de F. O mercado do livro didático no Brasil: da criação do Programa Nacional do Livro Didático (PNLD) à entrada do capital internacional espanhol (19852007). 2007. 252 f. Tese (Doutorado em Educação) - Pontifícia Universidade Católica de São Paulo. São Paulo, 2007.

ESPÍNDOLA, D. P. O uso do livro didático, em sala de aula, pelo professor de História. 2003. 204 f. Dissertação (Mestrado em Educação) - Universidade Federal de Minas Gerais. Belo Horizonte, 2003.

MANTOVANI, K. P. O programa nacional do livro didático - PNLD: impactos na qualidade do ensino público. 2009. 126 f. Disserta- ção (Mestrado em Geografia humana) Universidade de São Paulo. São Paulo, 2009.

RICHAUDEAU, F. Concepcion e producion des manuels scolaires: guide pratique. $\mathrm{Pa}$ ris: UNESCO, 1979.

RÜSEN, J. O livro didático ideal. In: BARCA, I.; MARTINS, E. de R; SCHMIDT, M. A. (Orgs.). Jörn Rüsen e o ensino de história. Curitiba: Ed. UFPR, 2011. p.109-127.

SANTOS, C. M. C. dos. O livro didático do ensino fundamental: as escolhas do professor. 2007. 236 f. Dissertação (Mestrado em Educação) - Universidade Federal do Paraná. Curitiba, 2007.

\section{(c) (i) \\ License information: This is an open- access article distributed under the terms of the Creative Commons Attribution License, which permits unrestricted use, distribution, and reproduction in any medium, provi- ded the original work is properly cited.}

Artigo recebido em 10 de dezembro de 2015.

Avaliado em 16 de setembro de 2016.

Aceito em 13 de outubro de 2016.

Publicado em 03 de novembro de 2016.

\section{Como citar este artigo (ABNT):}

NASCIMENTO, Bruno Rafael Machado. Por uma avaliação objetiva e fundamentada: a escolha do livro didático de História. Estação Científica (UNIFAP), Macapá, v. 6, n. 2, p. 79-89, maio/ago. 2016. 